\title{
Ciclos econômicos, morfologia urbana e sistemas territoriais em Urucará (AM)
}

\author{
Economic cycles, urban morphology and territorial systems in Urucará \\ (AM)
}

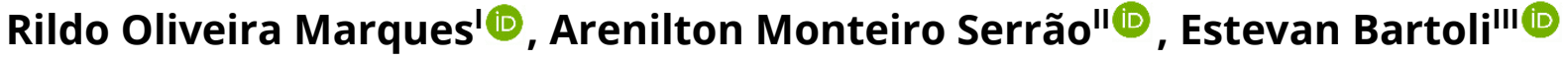 \\ ' Secretaria de Estado de Educação e Qualidade de Ensino do Amazonas, Barreirinha, AM, Brasil \\ "Secretaria de Estado de Educação e Qualidade de Ensino do Amazonas, Urucará, AM, Brasil \\ II Universidade do Estado do Amazonas, Departamento de Geografia, Parintins, AM, Brasil
}

\section{RESUMO}

A presente pesquisa tem por objetivo compreender o crescimento urbano de Urucará (AM) com base nos elementos que compõem a análise da morfologia urbana e as redes de sujeitos locais que dinamizam a economia da cidade e moldam o espaço intraurbano. Para se entender a atual forma e as dimensões do plano urbano, retomam-se aspectos históricos de como a cidade foi se alterando a partir de sua inserção na rede urbana regional por meio de surtos e declínios de ciclos político-econômicos e como isso se refletiu nos planos urbanos estabelecidos. Na sequência, analisa-se a morfologia urbana reconfigurada por sistemas territoriais: Urbano-Ribeirinho (ligado à economia popular) e Urbano-Fluvial (ligado ao capital mercantil e setores dominantes da economia local). Os resultados finais salientam que a expansão urbana é condicionada pelo fator sítio que limita ou potencializa sua apropriação e que a cidade enquanto forma tem possibilitado práticas espaciais a partir de diversas centralidades, condicionando um contínuo movimento entre a sede e interiores.

Palavras-chave: ciclos econômicos; morfologia urbana; sistemas territoriais; Urucará

\section{ABSTRACT}

The present research aims to understand the urban growth of Urucará (AM) based on the elements that compose the analysis of urban morphology and the networks of local subjects that boost the city's economy and shape the intra-urban space. In order to understand the current form and dimensions of the urban plan, aspects of historical of how the city was changing from its insertion in the regional urban network through outbreaks and declines of political-economic cycles and how this was reflected in the established urban plans. Next, the urban morphology reconfigured by territorial systems is analyzed: Urban-Riverside (linked to the popular economy) and Urban-Fluvial (linked to mercantile capital and dominant sectors of the local economy). The final results highlight that urban sprawl is conditioned by 
the site factor that limits or enhances its appropriation and that the city as a form has enabled spatial practices from various centralities, conditioning a continuous movement between the city headquarters and inland.

Keywords: economic cycles, urban morphology, territorial systems, Urucará

\section{INTRODUÇÃO}

A morfologia urbana está para além das formas geométricas especializadas nas cidades. A cidade é entendida por meio de processos históricos, geográficos e pela materialização e justaposição de planos urbanos no transcorrer das décadas.

A materialização dessas formas, no entanto, é moldada pelas redes de sujeitos que dinamizam a economia local, processo denominado em cidades com dinâmica ribeirinha/fluvial por Bartoli (2017) como "sistemas territoriais", que se subdividem em duas frentes de disputas, por setores da economia popular e da economia mercantil.

A retomada de processos ocorridos em ciclos econômicos regionais é o ponto de partida para entender a formação da cidade de Urucará (AM). Assim, retomam-se aspectos históricos de como a cidade foi se alterando a partir de sua inserção na rede urbana sub-regional e como isso se refletiu nos planos urbanos estabelecidos.

A presente pesquisa tem por objetivo compreender o crescimento urbano de Urucará (AM) com base nos elementos que compõem a análise da morfologia urbana e as redes de sujeitos locais que dinamizam a economia da cidade e moldam o espaço intraurbano.

A partir das propostas mencionadas acima foi possível pensar a estrutura do texto em três tópicos principais. No tópico 4 descreve-se como os períodos e fases econômicas refletiram-se no espaço intraurbano de Urucará até a pujança da produção de juta no médio Amazonas. Do prelúdio de ocupação pelos aruaques à fundação da cidade, dialoga-se com aspectos históricos locais e com acontecimentos em múltiplas escalas. 
No tópico 5, parte-se do apogeu da juta e declínio dessa produção às dinâmicas mais recentes que impulsionaram o crescimento e inversão populacional refletidos na expansão urbana, materializados em bairros periféricos e na formação de conjuntos habitacionais que caracterizam a fase atual de fragmentação e dispersão do tecido urbano. Em seguida, contextualizam-se os aspectos da cidade com os elementos que compõem a análise morfológica empreendida por Whitacker e Miyazaki (2012).

No tópico 6 discutem-se os sistemas territoriais e suas dinâmicas no espaço urbano com base na proposta de Bartoli (2017; 2018b). Elementos da economia popular (Sistema Territorial Urbano-Ribeirinho - STUR) e mercantil (Sistema Territorial Urbano Fluvial - STUF) presentes na cidade são conjugados para entender as alterações e adaptações em pontos estratégicos do espaço intraurbano (margens fluviais) que funcionam como nós multireticulares para dinâmica econômica existente e condicionada pelos cursos fluviais. A interpretação é que a relação entre sistemas territoriais (STUR e STUF) se manifestam na morfologia urbana de Urucará tanto pelas margens de rios quanto pelas funções que cumpre.

\section{LOCALIZAÇÃO DA ÁREA DE ESTUDO}

A cidade de Urucará está localizada no extremo leste do Estado do Amazonas e embora esteja entre as dez menores cidades em população do Estado do Amazonas, é sede de um dos maiores municípios em extensão territorial (27.903,4 $\mathrm{km}^{2}$ ), equivalente a 2.790.337 de hectares distribuídos em ampla extensão latitudinal. Limita-se a oeste com os municípios de São Sebastião do Uatumã (AM) e Presidente Figueiredo (AM); ao norte com o município roraimense de São João da Baliza (RR); ao leste com Nhamundá (AM); ao sul com Urucurituba (AM) e a sudoeste com Itapiranga (AM), Itacoatiara (AM) e Silves (AM). 
Figura 1 - Localização de Urucará - AM.

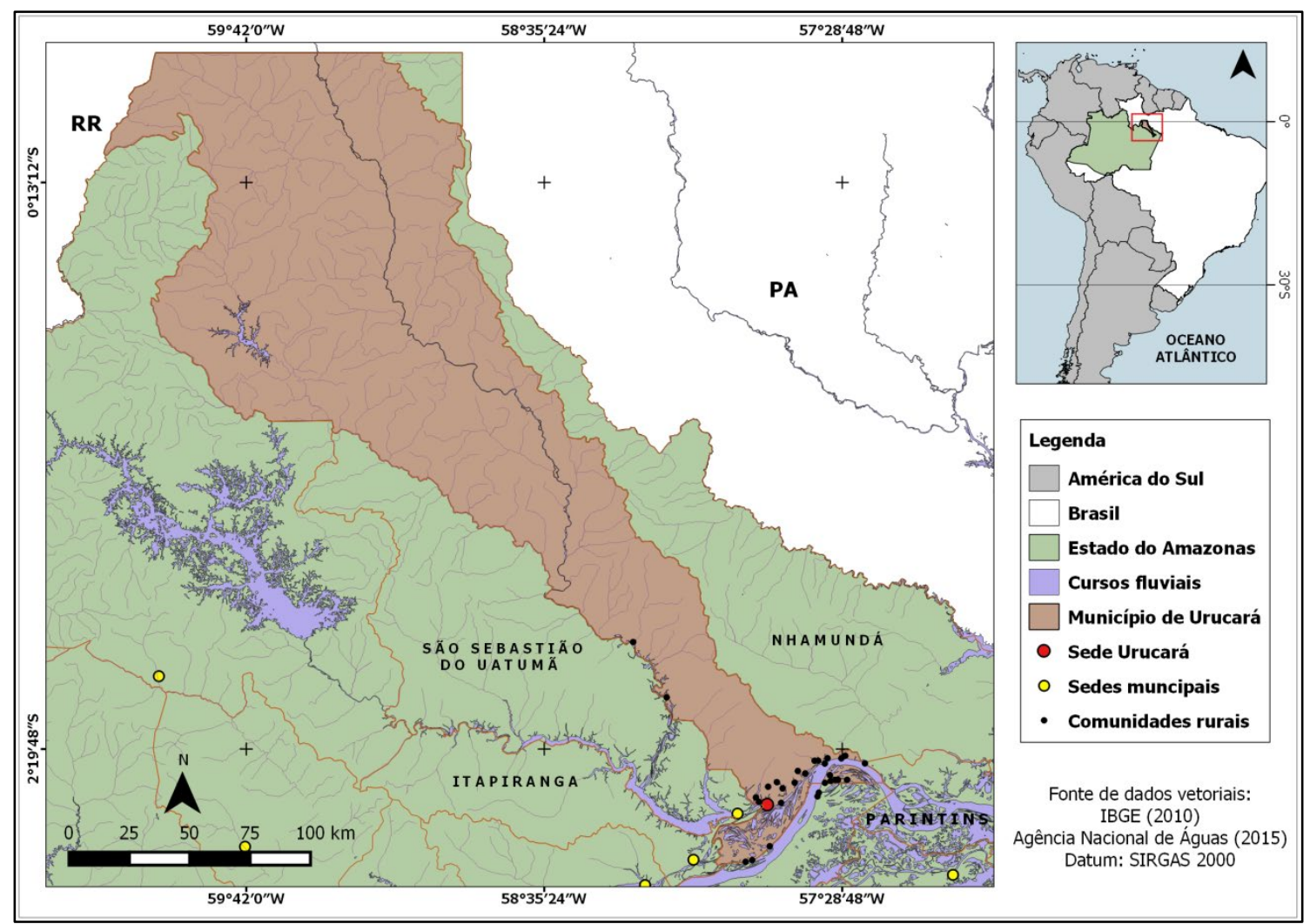

Fonte: Bases cartográficas do IBGE (2020).

A sede municipal situa-se na parte meridional do município, à jusante da confluência dos rios Uatumã e Maripá, tendo como principal acesso fluvial o paraná de Urucará, que tem seu curso inferior desembocando no rio Amazonas. A proximidade com a cidade, a grande oferta de pescado nos lagos de várzea, a possibilidade de cultivos agrícolas de curto ciclo e o acesso rápido ao rio Amazonas e consequentemente às cidades vizinhas, explica em grande parte a concentração de comunidades rurais na porção sul do município.

\section{PROCEDIMENTOS METOdOLÓGICOS}

Os procedimentos metodológicos adotados foram: levantamentos de dados primários em campo (aplicação de formulários), levantamentos de dados secundários nas secretarias de produção e de saúde, e confecção de material 
cartográfico, que permitiram não apenas a análise das formas, mas o conteúdo e os processos que compõe a morfologia urbana e a compreensão dos sistemas territoriais. A orientação teórico-metodológica da pesquisa teve como base as propostas de Whitacker e Miyazaki (2012), acerca dos elementos para caracterização da morfologia urbana; e a proposta de Bartoli (2017), sobre os Sistemas Territoriais, que condicionam a economia de cidades com dinâmica ribeirinha/fluvial.

No transcorrer do texto utilizam-se ainda conceitos e interpretações relacionadas à dinâmica urbana e territorial, sobretudo a contribuição de autores como Santos (1993), Raffestin (1993), Becker (2004), Corrêa (2006), Sack (2011), e Melo (2016).

\section{PERÍODOS ECONÔMICOS, OCUPAÇÃO DO TERRITÓRIO E FUNÇÕES HISTÓRICAS DE URUCARÁ}

Até o final do século XIX, a bacia do rio Uatumã era pouco conhecida na província do Amazonas. As inúmeras expedições científicas que partiram da Europa nos séculos XVIII e XIX não adentraram a referida bacia, motivo dos poucos relatos existentes sobre o processo histórico de ocupação. As lacunas não param por aí, pois são raros os registros sobre os povos indígenas que ocupavam esse território, as relações sociais estabelecidas com os brancos, a atuação das ordens religiosas e as redes de comércio existentes.

As primeiras ocupações humanas da bacia dos rios Uatumã e Jatapu transcendem as criadas pelos homens brancos que chegaram à região por volta do século XVII. A região já era ocupada há mais de 3 mil anos por sociedades caçadoracoletoras com alto grau de complexidade, como os povos do tronco linguístico aruaque ${ }^{1}$ (URBAN, 1992).

\footnotetext{
1 Dominavam a bacia do rio Negro, Uatumã, Jatapu e Urubu (FREIRE, 1984). Salientamos que não incluímos os índios caboquenas e bororos relatados nos escritos de Eustachio Libório da Cunha, pois não foi encontrado nenhum relato
} 
A migração dos aruaques para as bacias do rio Negro, Urubu e Uatumã ocorreu em distintos períodos, configurando como uma das dispersões mais antigas da bacia amazônica (PORRO, 1995). A chegada dos nativos na região foi motivada por vários fatores, entre os quais, guerras intertribais e as constantes perseguições que escravizavam por meio das tropas de resgate que atuavam nos rios Negro e Urubu.

No entanto, o contato com os colonizadores foi inevitável, primeiramente com os espanhóis e posteriormente com os lusitanos. Praticantes de uma rica agricultura, hábeis coletores e com amplo conhecimento sobre a pesca, os aruaques contavam com mais de um milhão de indivíduos (WRIGHT, 2003). Escravização, doenças, conflitos tribais, extermínio pelos brancos e invasões estão entre os principais motivos do desaparecimento dessas populações do atual território que compreende hoje os municípios de Urucará (AM), São Sebastião (AM), Itapiranga (AM) e Silves (AM).

Um dos primeiros núcleos de colonização que se tem registro foi criado pela Ordem Religiosa dos Franciscanos da Piedade, em 1708. Comandada por padres portugueses, a missão foi batizada de Jatapu, localizada nas proximidades do rio de mesmo nome. Como citado por Jobim (1957, p. 180):

Uma légua acima do Jatapu ou 16 da foz do Uatumã, na margem esquerda, pouco abaixo da ilha Uajará-Uacá, no igarapé Taracuera que corre para o Uatumã, os padres da Piedade fundaram, em 1708, uma missão, que depois de algum progresso foi destroçada pelos índios aruaques. No ataque abateram os dois missionários aludidos, Frei António de Vila Viçosa e Frei Pedro de Évora, e muitos moradores. Os índios incendiaram depois as barracas.

Assim como ocorreu em quase toda extensão da bacia amazônica, o processo de colonização foi marcado por resistência e muita luta dos autóctones. Com os aruaques não foi diferente, apesar das poucas evidencias históricas,

da ocorrência desses povos nesse território. Apenas Anísio Jobim (1947), faz referência a ocorrência desses grupos, no entanto, localizados no rio Urubu. 
antropológicas e arqueológicas sobre os nativos da bacia do Uatumã, a construção e a manutenção dessas missões não ocorreu de forma pacifica. As respostas para as rebeliões eram sempre marcadas pela violência. Como no caso da destruição da missão Jatapu, o governo do Grão-Pará imediatamente respondeu com crueldade a esse episódio.

As povoações que deram origem as cidades de Urucará, São Sebastiao do Uatumã e Distrito de Santana, ambas pertencentes ao município de Silves até 1887, eram compostas por colonos e camponeses, e só surgiriam no decorrer do século XIX. Segundo a comissão encarregada de colher dados estatísticos da província em 1839, a população residente nas missões e povoações que compunham os rios Jatapu (485 habitantes) e Uatumã (332 habitantes) somavam um total de 817 habitantes (BAENA, 2004). No entanto, as populações indígenas residentes nas cabeiras mais distantes não entravam nessa estatística.

O início do povoamento da localidade que hoje é Urucará ocorreu com a chegada de Crispim Lobo de Macedo, que era uma espécie de comerciante (regatão ${ }^{2}$, que saiu de Cametá, no Pará, e percorreu os mais longínquos rincões do paraná de Urucará e rio Uatumã nas primeiras décadas século XIX, estabelecendo-se nesse território com a família, escravos e agregados (TENÓRIO, 2016).

No entanto, ao que tudo indica, o sítio agrícola de Crispim Lobo de Macedo não surgiu pelo simples acaso, como então se imaginava. Foi pensado estrategicamente para resguardar os domínios da Coroa portuguesa nos rios Uatumã e Jatapu e possibilitar a exploração das "drogas do sertão" e posteriormente do látex, produtos valorizados na Europa. Os autóctones que não integraram esse sistema de exploração migraram para o curso superior dos rios, rumo ao norte, para além das fronteiras com as Guianas. Ocupar essas terras por

\footnotetext{
2 Mercador que tinha condições econômicas de manter um barco a motor, e que navegava pelos rios amazônicos praticando escambo.
} 
meio de colonos e mestiços, e aí instituir uma base agrícola e econômica era de fundamental importância, visto que, eram espaços a serem preenchidos no domínio do território.

Esse lugarejo ínfimo possibilitou a posse do território pelo poder simbólico. Crispim Lobo de Macedo não dispunha de poder militar para tal propósito, sua presença e os interesses pelo qual representava, simbolizava o poder português. Além do povoamento, outros interesses econômicos estavam por trás de tal incursão, como a extração da castanha, caça, expulsão, catequização e dizimação de etnias indígenas que habitavam a margem esquerda do paraná de Urucará.

Os índios aldeados, controlados pelos poucos colonos, foram fundamentais para o sucesso econômico e territorial nos primórdios da fundação de Urucará. Ainda que as evidências históricas sejam raras, os nativos, conhecedores de uma rica agricultura, de vastos conhecimentos sobre os rios da região e de produtos da floresta de alto valor econômico, eram explorados por meio de troca ou venda a entrepostos externos coloniais que drenavam essa produção para as redes urbanas mais complexas como Manaus e Belém, com base no sistema de aviamento, mecanismo fundamental na economia amazônica pós-período pombalino (CORRÊA, 2006).

O período que se estende de 1850 a 1920 corresponde ao período em que a rede urbana amazônica ganha nova dimensão econômica e espacial. Este contexto histórico tem como pano de fundo o "boom" do extrativismo da borracha, que revigorou tanto a economia como a rede urbana (CORRÊA, 2006). Os fatores que motivaram tal dinamismo estão associados a forte demanda externa da borracha, abertura da navegação do rio Amazonas, chegada da mão de obra nordestina e ofertas de capitais.

Em meio a esse contexto e fatores oriundos da produção extrativa, surgiu a necessidade de novos núcleos urbanos e o revigoramento dos já existentes. Um deles faz referência ao pequeno povoado de Nossa Senhora Santana da Capela, 
elevado em 1880 à categoria de freguesia, embrião do povoamento que mais tarde se chamaria Urucará.

A Lei $n^{\circ} 744$ de 12 de maio de 1887 elevou a freguesia de Nossa Senhora Santana da Capela à categoria de vila, com o nome de Vila de Nossa Senhora Santana de Urucará, tendo sido instalado o município no mesmo ano. A Lei estadual $n^{\circ} 33$, de 04 de novembro de 1892, determinou que a povoação de Santana de Urucará passasse a chamar-se simplesmente Urucará. Em divisão administrativa referente ao ano de 1911, a vila é constituída do distrito sede e pelo Decreto-lei estadual $n^{\circ} 68$ de 1938 o distrito sede é elevado à condição de cidade com a denominação de Urucará (IBGE, 2020).

Nesse período, os circuitos mercantis intrarregionais de navegação eram muito dependentes das demandas externas ligadas à exportação. No início do século XX, o "boom" da borracha dinamizou alguns núcleos urbanos na Amazônia, pela ocorrência do látex nas cabeceiras ${ }^{3}$ dos principais rios, Urucará é então inserido na rota de navegação do estado do Amazonas. Duas vezes ao mês, navios da Companhia de Navegação e Comércio do Estado do Amazonas atracavam na vila de Crispim Lobo de Macedo e abasteciam com a borracha oriunda dos seringais dos rios Uatumã e Jatapu (GONÇALVES, 1903). Outros produtos de exportação também eram embarcados, como a castanha, óleos de copaíba e andiroba.

Esse fato fez com que as cidades funcionassem como meros entrepostos de escoamento da borracha, não constituindo elites locais, tampouco acúmulos de capitais devido ao sistema de aviamento contemplar vantagens às casas aviadoras localizadas em Manaus. Consequentemente, tais cidades não formaram divisões sociais e territoriais do trabalho, nem complementações de funções ou trocas dentro da rede urbana, sendo tal processo denominado como "proto-urbanização" (MACHADO, 1999).

\footnotetext{
${ }_{3}^{3}$ Área onde fica a nascente dos cursos fluviais. É o oposto de foz (GUERRA; GUERRA, 2011).
} 
A partir de 1912, a borracha brasileira, que chegou a abastecer vários segmentos de setores industriais pelo mundo, passou a sofrer concorrência dos seringais asiáticos sob domínio inglês, e as disputas no mercado internacional tornaram o produto brasileiro muito caro, principalmente devido às profundas diferenças no modo de produção. Em crise, a economia da borracha causou declínio na dinâmica na rede urbana da Amazônia Ocidental e impactou a economia de pequenas cidades ligadas ao circuito de aviamento, tendo causado alteração de correntes migratórias e até esvaziamento populacional dessas cidades. Urucará, assim como a maioria das cidades, possivelmente sofreu poucos impactos indiretos.

Com essa ausência de funções urbanas e o declínio da produção extrativa, especialmente pela diminuição da oferta do látex no mercado internacional entre as décadas de 1910 e 1930, o município de Urucará entrou em estagnação por longas décadas, não atendendo mais aos interesses capitalistas que drenavam as riquezas agroextrativas. Outros produtos de menor valor passaram a ser a principal via de ligação com as metrópoles regionais. No entanto, a falência das casas aviadoras em cidades como Belém e Manaus, implicou diretamente na diminuição do tráfego de navegação pelos rios Jatapu e Uatumã, condição que prevalecerá até o "boom” da juta, nas décadas de 1960-70.

Nas primeiras décadas do século XX, a vila de Urucará, se configurava como um pequeno povoado composto pela mistura interétnica de alguns poucos moradores brancos ${ }^{4}$. A população majoritária era composta pelo cruzamento de colonos paraenses e indígenas. Com o apogeu da produção de borracha nas cabeceiras dos rios da região, algumas famílias nordestinas reforçaram ainda mais esse cruzamento, compondo força de trabalho nos seringais, mantendo a agricultura como base de sustentação familiar.

\footnotetext{
${ }^{4}$ Antigos colonos paraenses, migrantes europeus como portugueses, italianos, turcos e libaneses.
} 
Na década de 1920, antigas cabanas de parede de taipa e cobertura de palha de buçu, dividiam espaço com boas casas, construídas de pedras e cobertas com telhas. O pequeno povoado de Urucará contava com uma pequena igreja, construída em pedras, coberta de telhas e piso de cimento. Apesar da importância que o período da borracha (1850 a 1920) teve sobre a região dos Uatumã e Jatapu, este impactou de forma modesta a infraestrutura inicial urbana e a arquitetura urucaraense. Estruturou timidamente a configuração inicial do plano urbano, porém contribuiu para a consolidação do centro comercial e administrativo.

Após a primeira Guerra Mundial (1914-1918), a região amazônica vivenciava um período de declínio econômico, com estagnação das pequenas cidades, ainda que estas não estivessem diretamente envolvidas com a produção do látex. A partir de 1933, entre o trecho de Manaus e Santarém, teve início a implantação do ciclo da juta partindo de Parintins (AM), que foi polo propulsor das experimentações no plantio da fibra vegetal destinada a produção de sacarias para exportação do café brasileiro. O Governo Federal, em 1930, concedeu permissão para órgãos japoneses fundar em Parintins o Instituto de Estudos Agrícolas para imigração japonesa, na Vila Amazônia, próximo ao núcleo central (ROSAL, 2000).

Esses acontecimentos foram essenciais para a configuração da morfologia urbana em algumas cidades ribeirinhas como Urucará, onde os aspectos ligados ao ciclo econômico da juta modificaram timidamente as formas da cidade.

Portanto, a criação do município de Urucará está ligada a legados históricos na formação da região amazônica como aponta Becker (2009), tendo uma ocupação tardia e dependente do mercado externo na periferia da economiamundo. Surtos de valorizações momentâneas de produtos no mercado internacional incitaram o controle do território e a imposição da lógica mercantil externa, o que acabou culminando no acelerado processo de urbanização. Resumindo, a discussão sobre as alterações morfológicas de Urucará foram consequência das alterações de sua inserção na divisão social e territorial do trabalho, sempre ligadas às variações reflexas da economia mundo. 


\section{PROCESSO URBANO E MORFOLOGIA: DO CICLO DA JUTA À FRAGMENTAÇÃO DO ESPAÇO INTRAURBANO RECENTE}

Os padrões de ocupação em Urucará começam a ser alterados a partir de meados da década de 1950, quando enchentes/cheias e indisponibilidade de terras nas várzeas forçaram mudanças permanentes do campesinato para as áreas de terra firme. Na ocasião do recenseamento de 1950, o município de Urucará possuía pouco mais de 3.672 habitantes, destes, apenas 649 residiam na sede (18\% da população). O intercâmbio comercial era mantido com as praças de Manaus, Belém, Fortaleza, Rio de Janeiro e municípios limítrofes. Parte considerável da juta cultivada em Urucará passou a ser processada em Parintins, diminuindo ainda mais as funções de mediação exercidas por Urucará e acúmulos de capitais pelos pequenos empresários e elites locais.

Em se tratando de Amazônia, esta diferenciação de tempos espaciais (Santos, 1996) é muito marcante na consolidação da rede urbana. Bartoli (2017) destaca que os distintos períodos históricos alteraram consideravelmente a composição de cidades do baixo Amazonas 5 , ligadas aos ciclos econômicos da juta, pecuária e outros componentes da extração da renda da terra ${ }^{6}$, realidade que se assemelha a configuração socioespacial da cidade de Urucará.

Ainda que a produção do cacau tenha gerado riquezas para um punhado de comerciantes-patrões que atuavam nas embocaduras dos principais rios da região no início do século $X X$, foi o cultivo, o apogeu e a decadência da juta durante as décadas de 1960/70, que deixaram marcas na morfologia urbana da cidade, evidenciando o florescimento nos momentos de surtos de pequenos comércios, firmas e manufaturas, submergindo estas com seu declínio (BECKER, 2013).

\footnotetext{
${ }^{5}$ Denomina-se como baixo Amazonas a sub-região de planejamento composta pelos municípios de Urucará, Boa Vista do Ramos, Barreirinha, Maués, São Sebastião do Uatumã, Nhamundá e Parintins.

${ }^{6}$ Fruto do trabalho não pago, valor materializado na confecção da mercadoria produzida pelo camponês (PAULINO, 2012).
} 
O cultivo da juta (figura 1) contribuiu com mais da metade das receitas das atividades agrícolas, complementados pela mandioca, macaxeira, fumo, feijão, cacau, café, milho e banana (BRASIL, 1956). A pecuária contava com pouco mais de 3.500 suínos, 1.700 bovinos, 600 ovinos, contribuindo modestamente nas receitas do município. Somando-se a isso, a caça predatória de jacarés, veados, onças, caititus e outros animais que forneciam peles e couros para exportação, representavam o outro elo da cadeia produtiva urucaraense.

Figura 2 - Fibras de juta estendidas ao sol para secagem.

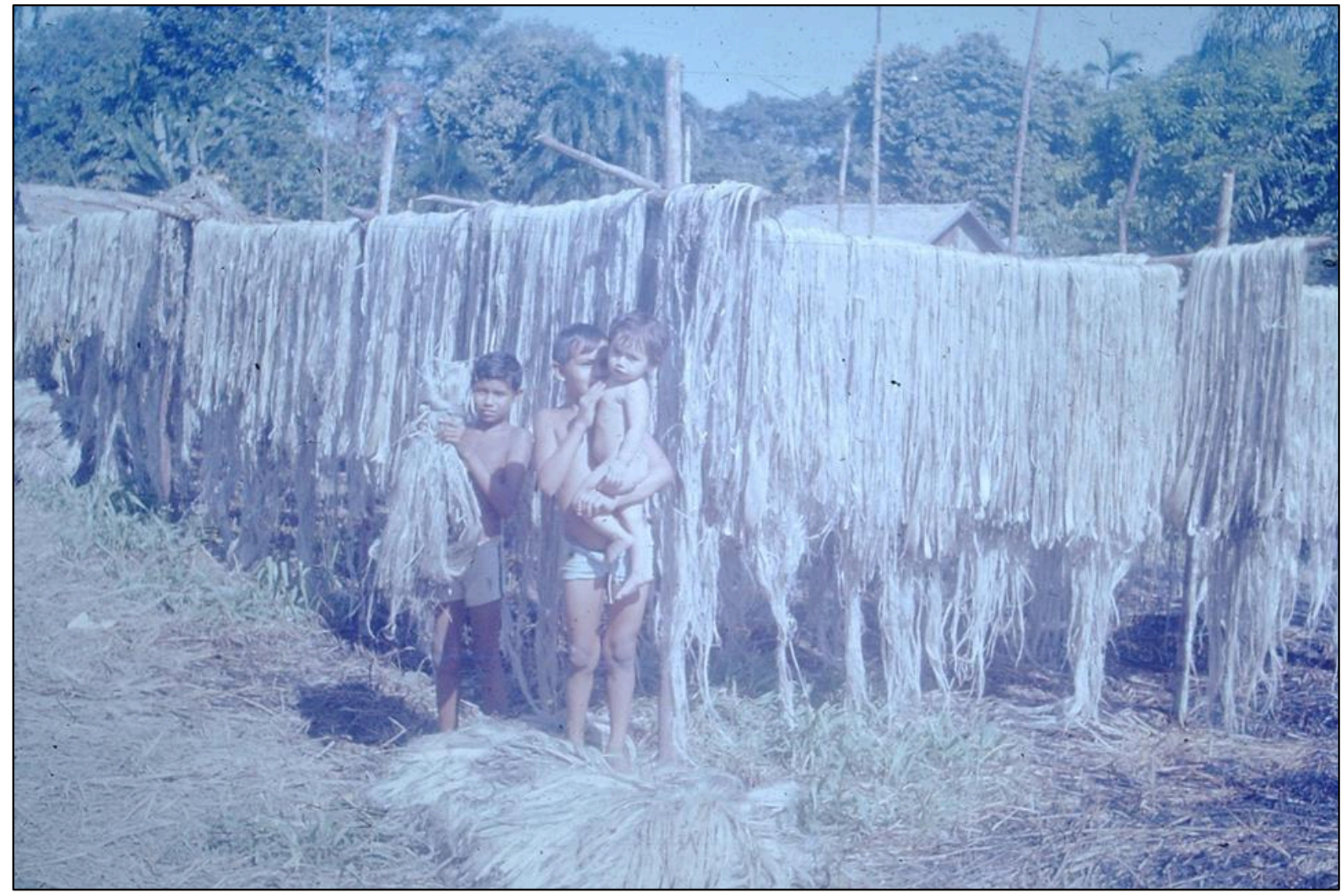

Fonte: Arquivo pessoal da família Clinton, Urucará, anos 1970.

A vocação pela produção agroextrativa de exportação não foi capaz de criar novas divisões sociais do trabalho, nem condições para a expansão econômica que possibilitasse o desenvolvimento da cidade de Urucará. Becker (2013) chama esse processo de trabalho novo, condição não alcançada pela maioria das cidades 
amazônicas, devido à baixa dinâmica interna, curtos surtos de expansão econômica (ciclos econômicos) e ligação de dependência e subalternidade com urbes externas, relação de centro-periferia.

Essas condições foram cruciais para os poucos aparatos técnico-científicos e informacionais (Santos, 1996) materializados no território do baixo Amazonas, pois distantes dos centros mais dinâmicos regionais, a estagnação e baixo dinamismo se acentuaram com o predomínio do modelo Zona Franca de Manaus (posteriormente transformada em Polo Industrial). De acordo com Meirelles (2008), ao longo da história do Amazonas podemos perceber uma constante crise no setor primário e o empobrecimento do homem do interior. Os planos de desenvolvimento propostos para o Estado do Amazonas geraram tímidas melhoras depois de 40 anos e o desenvolvimento continua concentrado em torno da Zona Franca.

As rugosidades (Santos, 1996) do período da juta, bem como os poucos fixos construídos (armazéns, galpões e fábrica de beneficiamento) ficaram apenas nas lembranças dos moradores mais antigos. O curto ciclo econômico, capaz de deixar marcas na economia entre as décadas de 1950 e 1980, não foi capaz de amenizar as desigualdades socialmente materializadas no território. As principais estruturas físicas oriundas da produção de fibras ficaram restritas à cidade de Parintins, destacando a centralidade que essa cidade vem desempenhando ao longo das décadas sobre os demais municípios, condicionando os produtores de Urucará a meros fornecedores de matéria prima.

Essas relações remetem entender a cidade de Urucará inserida num contexto passível de interpretação a partir dos elementos espaciais presentes na proposta (Raffestin, 1993), acerca de tessituras, nós e redes. No transcorrer do ciclo da juta, as relações territoriais se fortalecem, com Urucará cumprindo um papel de nó pouco relevante no cenário da economia regional.

A partir da década de 1970, a produção da juta apresenta seus primeiros sinais de declínio. Os efeitos dessa crise foram amplamente sentidos pelo 
camponês do baixo Amazonas, que tinha nesse produto importante alternativa de renda, trabalho e mercado. Entretanto, a pesca do pirarucu representou por décadas uma das principais alternativas econômicas. A disponibilidade de complexos de lagos localizados em área de várzea possibilitou a captura em grande escala. Barcos regatões oriundos de cidades do estado do Pará compravam a espécie já seca (salgada) dos pescadores locais na década de 1970 (figura 2). Em troca do peixe seco deixavam mercadorias, relação semelhante aos estabelecidos pelos comerciantes-patrão do período da juta, ou seja, a prática do aviamento. Isso demonstra a antiga relação da exploração do campesinato fortalecendo setores do capital mercantil.

Figura 3 - Comércio do pirarucu seco (esquerda) e barco regatão paraense (direita).

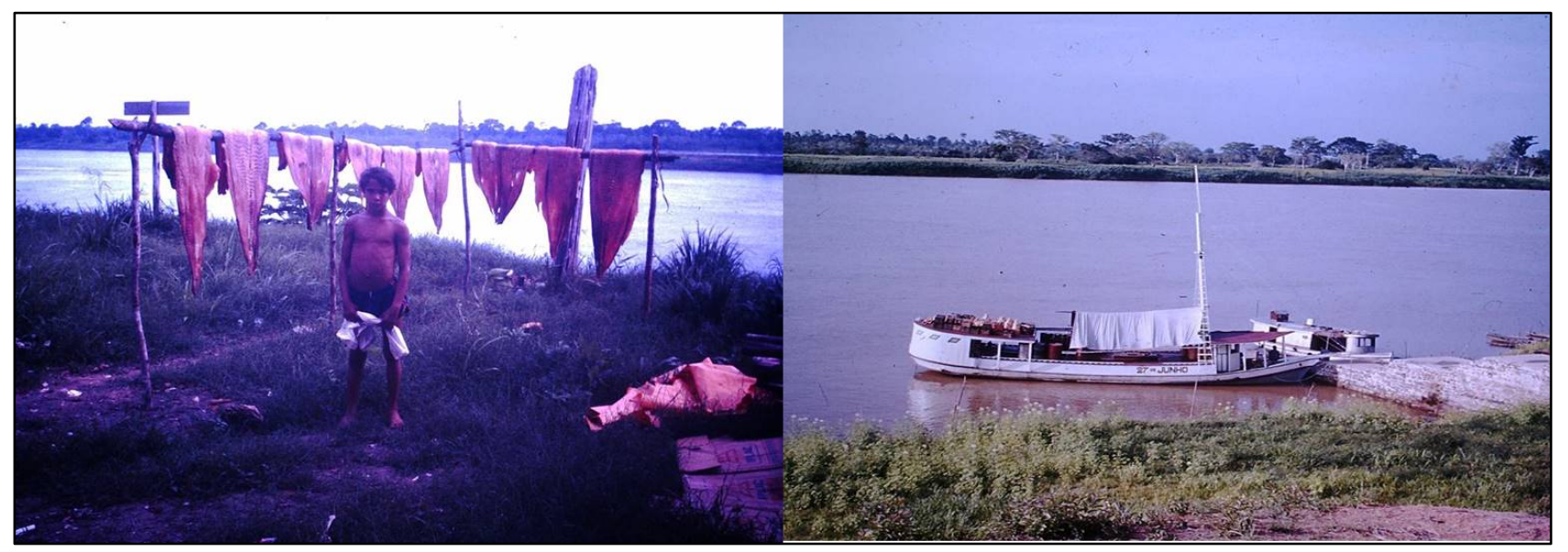

Fonte: Arquivo pessoal da família Clinton, Urucará, anos 1970.

O êxodo rural decorrente desses fatores acarretou mudanças estruturais no espaço urbano urucaraense, ocasionando o surgimento dos bairros São José, Centro e São Jorge que formaram o plano urbano inicial de Urucará durante as décadas de 1960-70. A Rua Crispim Lobo, Coronel Pinto e Antenor Thiago de Melo compunham os principais traçados da cidade, marcados por poucos casarios que indicam ciclos econômicos passados. A margem fluvial central hoje indica ser o principal referencial da dinâmica econômica municipal. 
A partir das décadas de 1980 e 1990 houve a expansão do plano urbano. O surgimento de bairros como Aparecida, Santa Luzia, Divino, Paraíso e São Pedro ampliaram consideravelmente a população urbana. As mais recentes ocupações do sitio urbano se deram entre as décadas de 2000 e 2010. A formação dos bairros Cafezal, Beija-Flor, Glória e Nova Jerusalém, foi o ponto de inflexão para inversão do perfil populacional do município (quadro 1), característica semelhante a outras pequenas cidades do baixo Amazonas.

Quadro 1 - Evolução demográfica e inversão populacional do município de Urucará.

\begin{tabular}{|c|c|c|c|}
\hline Décadas & Pop/absoluta & Pop/ Campo & Pop/ Cidade \\
\hline 1980 & 8. 761 hab. & 5. 303 hab. & 3.458 hab. \\
\hline 1990 & 11.328 hab. & 5.185 hab. & 6.143 hab. \\
\hline 2000 & 18.372 hab. & 10.274 hab. & 8.098 hab. \\
\hline 2010 & 17.094 hab. & 7.208 hab. & 9.986 hab. \\
\hline 2019 & 16.256 hab. & - & - \\
\hline
\end{tabular}

Fonte: IBGE.

Em 2018, novas áreas de ocupação sinalizaram para o grande déficit habitacional que vem passando a cidade. A pressão por moradia, determinada em parte pelo esvaziamento crescente do campo, pela busca de serviços essenciais de educação, saúde e emprego, vem motivando o surgimento de ocupações irregulares e conjuntos habitacionais, dando novos contornos na configuração socioespacial de Urucará. Sem infraestrutura básica como asfaltamento, coleta de lixo, esgoto, energia elétrica e ausência de ocupação remunerada, a informalidade é uma marca presente na vida dessas famílias, que possuem ligação embrionária com o campo, complementando sua renda com atividades camponesas e com os circuitos territoriais.

Urucará tem traçado ortogonal como a maior parte das cidades do Amazonas. As duas principais ruas comerciais, Crispim Lobo e Cel. Pedro Cunha, coincidem com o marco inicial da cidade e se estendem pela margem fluvial central. O comércio e serviços não se concentram apenas nessas ruas, mas encontram-se 
dispersos em algumas ruas da área central. Mesmo condicionado por forte dinâmica fluvial, o tecido e os limites físicos do sítio revelam certo planejamento e adequação das vias que, ainda que mantendo um padrão ortogonal, permite a circulação por vias paralelas aos cursos fluviais e acesso a portos populares para uso econômico. A planta da cidade revela que os bairros centrais, mais antigos, possuem quadras e terrenos maiores em relação aos loteamentos recentemente incorporados que, na maior parte dos casos, estão afastados do centro (figura 3). Atualmente a cidade possui $10,9 \%$ de domicílios com esgotamento sanitário adequado, 90,8\% de domicílios em vias públicas com arborização e 10,2\% de domicílios em vias públicas com urbanização adequada (IBGE, 2020).

Figura 4 - Expansão do plano urbano de Urucará por décadas e uso do solo nas beiras de rios.

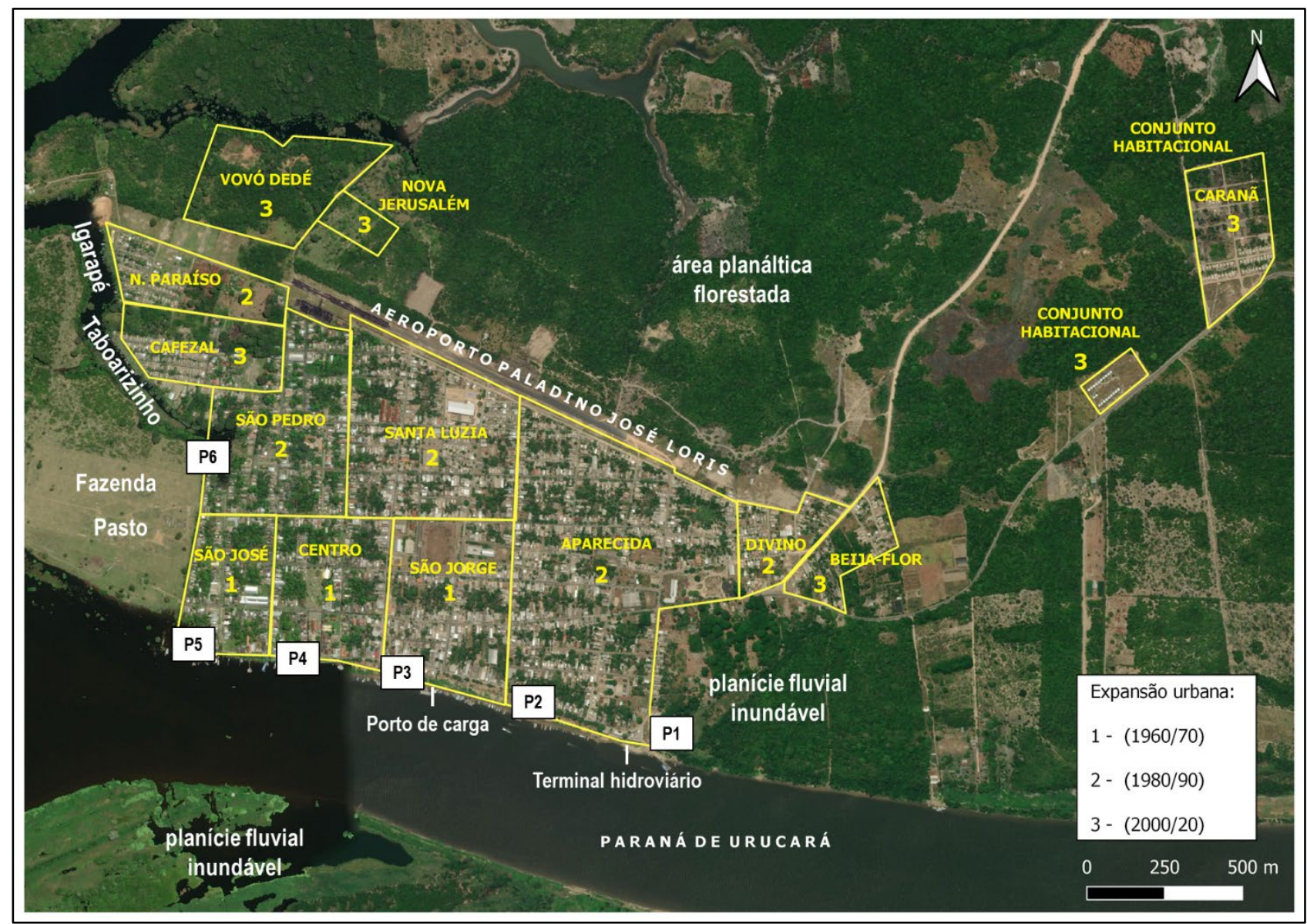

Fonte: Google Earth. 
Legenda: A descrição do uso nas beiras de rios (P1 a P6) serão apresentadas no quadro 2.

Ainda que não tenha as marcantes contradições das cidades médias e grandes, é possível notar que a paisagem urbana de Urucará expressa diferenças na distribuição de renda e de acumulação de capital. Deste exercício, é possível observar que, guardadas as devidas proporções, cada pequena cidade revela as contradições sociais marcadas pela lógica capitalista e que se contrapõem à lógica das necessidades humanas (ENDLICH, 2011). A área central da cidade, por exemplo, compõe o centro comercial e administrativo, e ainda é o lócus de residência das famílias tradicionais com melhores condições socioeconômicas e também onde se concentram a maior parte dos espaços de lazer como quadras poliesportivas, praças e portos com melhor infraestrutura.

A baixa complexidade da dinâmica econômica e a recorrente associação a espaços socialmente acolhedores e tranquilos, sem os altos índices de violência e trânsito caótico como nas grandes e médias cidades, podem camuflar a estrutura de uma sociedade divida em classes. Porém, a análise morfológica e o reconhecimento dos reflexos de processo mais amplos no espaço intraurbano podem desmistificar interpretações equivocadas sobre as pequenas cidades.

Sistematizados por Whitacker e Miyazaki (2012), os elementos para caracterização em morfologia urbana são fundamentais para análise de cidades com dinâmicas ribeirinhas e fluviais. Seus apontamentos metodológicos têm como base: O plano urbano e a evolução do plano; As relações do plano com o sítio urbano; A fisionomia urbana; A relação entre o que é edificado e o que não é edificado; A densidade da ocupação e a Identificação de áreas morfologicamente homogêneas e heterogêneas.

O plano urbano e a evolução do plano: Whitacker e Miyazaki (2012) consideram avaliar os períodos de implantação, os determinantes de cada plano, as relações do plano com a circulação e com os demais componentes da morfologia em distintos momentos. Urucará expressa diferenças no formato e 
traçado das quadras e no desenho do tecido urbano, podendo ser interpretadas como possíveis mudanças na implantação dos planos urbanos em três momentos distintos: o primeiro, impulsionado pelos ciclos da borracha e juta (décadas de 1960/70), revela um traçado ortogonal formando quarteirões com formato grosseiramente quadrados; o segundo (décadas de 1980/1990), com o declínio da juta e aumento da demanda por moradia na cidade devido às cheias e indisponibilidade de terras na várzea, apresenta quadras mais retangulares e adequação à implantação da pista de pouso do aeroporto; e o último, a mais recente etapa de expansão urbana (2000/20), resultado do surto populacional das últimas décadas, reflete um desenho urbano com descontinuidades, dispersão e formas das quadras e arruamentos mais irregulares.

As relações do plano com o sítio urbano: conforme Whitacker e Miyazaki (2012) se dão, sobretudo, entre o plano e a topografia, os limites físicos, os acidentes geográficos, que possuem certo grau de determinação sobre a implantação e a expansão do sítio urbano, assim como a função urbana predominante instituída pela origem do povoamento. Em cidades ribeirinhas cabe averiguar a sazonalidade do regime hídrico amazônico, os impactos de planos assentados em sítios constituídos por arquipélagos fluviais, ilhas, várzeas baixas, terraços e se o plano urbano se adequa a rede hidrográfica que entrecortam as cidades. Embora não esteja localizada no curso principal do rio Amazonas, a cidade de Urucará encontra-se em posição privilegiada e com acesso fluvial entre duas cidades médias, Itacoatiara e Parintins. O plano urbano inicial está assentado sobre um terraço fluvial da planície Amazônica posicionado acima no nível das enchentes, com limitações de expansão ao sul e oeste pelo paraná de Urucará e seus afluentes, e ao norte pela pista do aeroporto, que condicionou uma barreira física à potencial expansão. Nas últimas décadas a expansão urbana ganhou força a partir do crescimento populacional urbano em 2010 e encontra-se em curso a leste e noroeste da sede na forma de ocupações irregulares recentes e conjuntos habitacionais. 
A fisionomia urbana: Whitacker e Miyazaki (2012) propõem que a noção de fisionomia urbana pode ser substituída pelo conceito de paisagem, em seu sentido geográfico. Assim, na análise morfológica a paisagem é tomada, num primeiro momento de apreensão em sua dimensão mais imediata e sensorial. Incluem-se elementos arquitetônicos, referenciais, contínuos ou fragmentados, representativos do poder estatal ou privado. Em cidades ribeirinhas é possível considerar, partindo dos elementos naturais e sociais de forma dialética, elementos que indiquem constante processo co-evolutivo: descrição de construções, embarcações e margens de rios. Evidencia a fragmentação urbana e permanência de elementos de ciclos passados: casarões, antigas moradias do marco inicial da cidade, galpões antigos, moradias populares e, no caso de cidades com dinâmica fluvial como Urucará, atenção à tipologia das embarcações (BARTOLI, 2017; 2018b) que denotam territorialidades específicas no uso popular ou de frações do capital mercantil dispostas nas beiras rios.

A relação entre o que é edificado e o que não é edificado: nesse caso Whitacker e Miyazaki (2012) propõem que se observem as áreas edificadas e as não edificadas, sempre uma em relação à outra e destas com o conjunto da cidade. Essa relação (edificado - não edificado) pode ser avaliada tanto para se procurar identificar os vazios urbanos, tomando-se a cidade como um todo, quanto na avaliação das relações entre a edificação e seus espaços abertos. Para cidades ribeirinhas como Urucará é possível notar limites de construção condicionados por relevos nas margens de rios ou pontas de ruas em forma de aglomerações palafíticas, como nos bairros São Pedro e São José. Nas proximidades de falésias fluviais são comuns espaços pouco edificados pela desvalorização devido às perdas de solo de propriedades pela vulnerabilidade geológica e condições geomorfológicas do relevo (altura e verticalidade da encosta fluvial).

A densidade da ocupação e a identificação de áreas morfologicamente homogêneas e heterogêneas: Para Whitacker e Miyazaki (2012) devem ser compreendidas sempre de maneira relacional comparando-se, no contexto 
analisado (a cidade, o loteamento, o conjunto de cidades), as áreas mais densas e as áreas menos densas. Com uma densidade demográfica de 0,61 hab/km² (IBGE, 2020), Urucará tem uma das menores populações relativas do Amazonas ( $47^{\circ}$ de 62 municípios do Estado). As diferenças de densidade estão materializadas na paisagem urbana pela diferença e tamanho de lotes entre as áreas próximas ao centro e bairros mais antigos (menor densidade) e os bairros populares e periféricos (maior densidade). Em locais inundáveis ou próximos de acesso a rios, áreas homogêneas têm relação entre relevo e o tipo de ocupação urbana: áreas inundáveis/aglomerados palafíticos; áreas de portos navegáveis o ano todo/setores dominantes e; áreas de portos com margem do tipo falésia fluvial/ocupação e adequação por setores da economia popular.

\section{SISTEMAS TERRITORIAIS E DINÂMICAS NO ESPAÇO URBANO}

Pesquisas recentes têm realizado esforços para compreender o caráter dinâmico, processual e relacional das cidades na Amazônia (TRINDADE JÚNIOR, 2010; MONTE-MÓR, 1994; BROWDER e GODFREY, 2006; BECKER, 2004; 2013), que devido ao caráter incompleto de suas economias (SANTOS, 1993), acabam não gerando funções urbanas (produtivas ou de serviços), e consequentemente implicando que populações estabeleçam vínculos territoriais com áreas interioranas. Nesse sentido, forma-se uma complexa e diversificada economia popular em cidades ribeirinhas visando complementos de renda, mas com intensa articulação com setores mercantis urbanos.

Possuindo circunscrição espacial a partir da maneira com que redes de sujeitos locais se articulam aos recursos da cidade (instituições diversas, mercados, coletivos organizados, empresas, etc.), territórios usados nas áreas de entorno das cidades se conectam aos bairros populares, formando diversas complementações e sobreposições. Por se tratar de relações de poder conformando estratégias para ordenamento territorial, essa economia popular vem sendo estudada a partir da 
proposta analítica de Bartoli $(2017 ; 2018 a)$, que a denomina enquanto Sistema Territorial Urbano-Ribeirinho (STUR).

Resumidamente, o STUR é composto pelo funcionamento e dinâmica da economia popular em cidades com dinâmicas fluviais e ribeirinhas. As redes de sujeitos do STUR realizam mediações e articulam a cidade a áreas de entorno subregional. Transportam produtos industrializados para interiores e retornam abastecendo o mercado urbano de recursos regionais. Receptam e processam produtos regionais na economia popular de bairros, consomem produtos industrializados, máquinas e insumos fornecidos pelo setor mercantil dominante, denominado como Sistema Territorial Urbano Fluvial (STUF). Essa reterritorialização do STUR molda a morfologia urbana pela formação de bairros (ocupações irregulares), formando conjunto de fixos referenciais (nós multireticulares) que possibilitam suas atividades como as margens fluviais em bairros populares. Geralmente os sujeitos possuem atividades econômicas nos interiores e na cidade (economia dual), prevalecendo uso de embarcações pequenas e médias de madeira (BARTOLI, 2017; 2018a; 2018b).

O STUF composto pelo capital mercantil urbano é articulado a escalas diversas na rede urbana. Empresas comerciais distribuidoras de produtos industrializados recebem e processam produtos regionais: entrepostos pesqueiros, madeireiras, postos de combustíveis, fábricas processadoras de polpas de frutas, matadouro, frigoríficos, supermercados, etc. Possuem domínio do comércio local de bens de consumo, máquinas e insumos, realizando relações escalares intensas com o exterior do sistema territorial (metrópoles regionais principalmente), articulando a rede urbana. O STUF impulsiona a busca por recursos regionais fornecendo fluxos adjacentes (MORAES, 2012), necessários para o funcionamento do STUR: gelo, combustível, alimentos, etc. Molda o espaço intraurbano a seu favor construindo fixos como portos privados, galpões, etc., com uso de grandes embarcações de ferro. 
Os dados obtidos por meio da aplicação de formulários a proprietários de embarcações pequenas e médias pertencentes ao STUR relevam que assim como em Parintins, em Urucará ocorrem forças centrífugas e centrípetas relacionadas ao consumo urbano. As populações residentes nas comunidades rurais abastecem a cidade com produtos agrícolas e acabam retornando com uma série de produtos industrializados adquiridos nos comércios locais. A alta demanda de alimentos e produtos industrializados, cujo consumo vem alterando cada vez mais os itens da dieta regional amazonense, são amplamente observados em embarcações de saída para as comunidades rurais. Frango congelado, frios em geral, conserva e embutidos estão entre os principais produtos que passam a ser consumidos nos interiores.

Os setores da economia popular (STUR) e ligados ao capital mercantil (STUF) utilizam pontos estratégicos no espaço urbano (margens de rios, principalmente) para manter práticas que se conjugam. Notadamente, os setores dominantes se apropriam de práticas espaciais dos setores populares (saber navegar e transitar pelos rios) na distribuição de bens industrializados para os interiores (comunidades rurais) e estes retornam à cidade com suas embarcações repletas de produtos regionais (figura 4). 
Figura 5 - Produtos agrícolas que chegam a Urucará das comunidades.

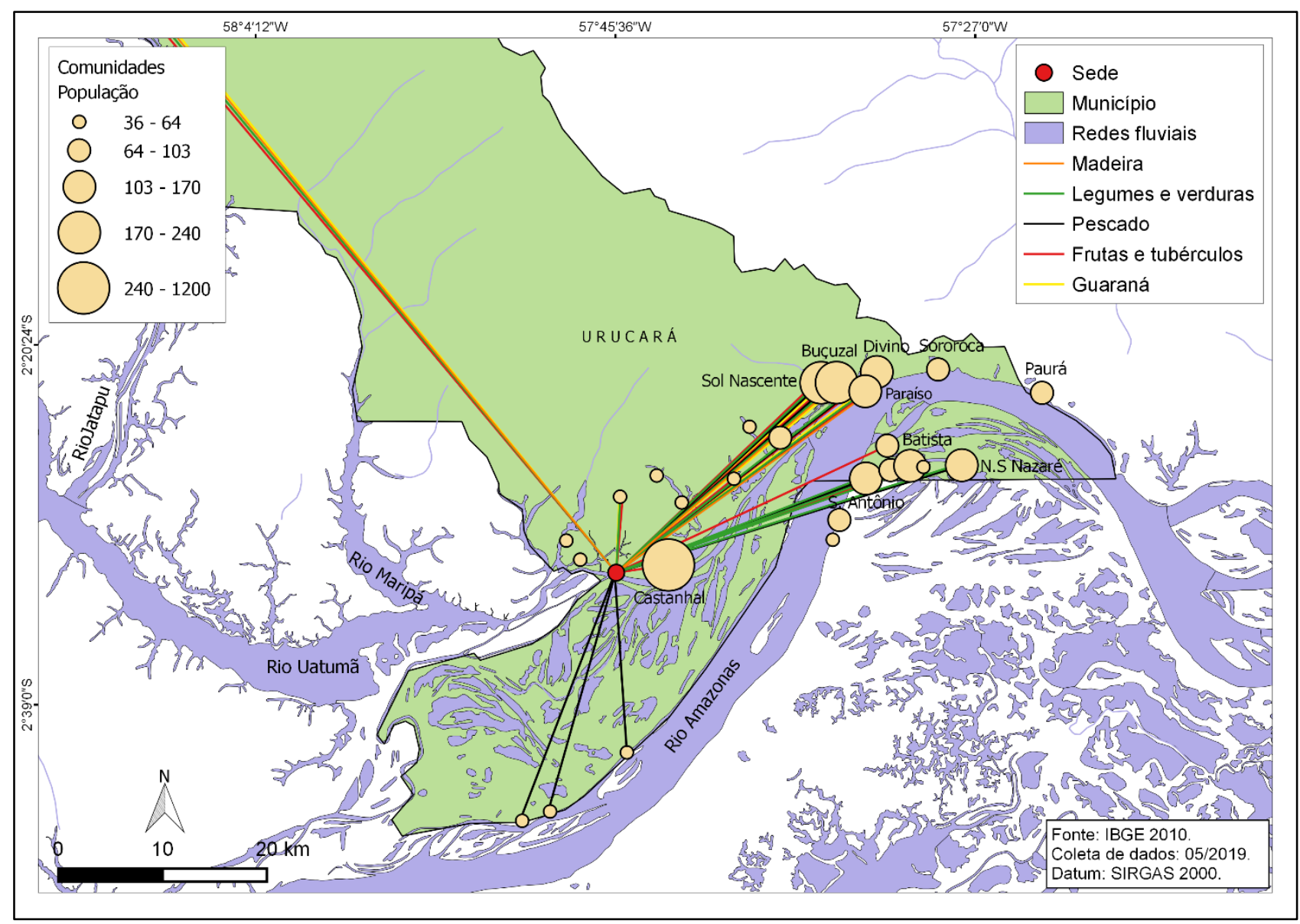

Fonte: Organização dos autores (2020).

A maior parte das comunidades de Urucará se concentra a leste da sede municipal, nas proximidades do rio Amazonas, em ambiente de várzea e terra firme. O mapa destaca especializações produtivas, como o guaraná, o pescado, legumes e verduras, com destaques às comunidades Castanhal, Buçuzal e Sol Nascente (consideradas distritos) e uma série de aglomerados menores do entorno.

Entre as principais comunidades do município estão: Castanhal (1200 habitantes), Buçuzal (240 habitantes), Sol Nascente (238 habitantes), Santo Antônio (170 habitantes), Paraíso (162 habitantes), Divino (140 habitantes), Adventista (136 habitantes), São Pedro (103 habitantes) e Jabote (102 habitantes) ${ }^{7}$. Essa intensa

\footnotetext{
${ }^{7}$ Dados populacionais fornecidos pela Secretaria Municipal de Saúde de Urucará.
} 
circulação entre cidade e comunidades depende na maioria dos casos da

navegação e de pontos de acesso fluvial no espaço intraurbano, que são apropriados de forma diferenciada (quadro 2).

Quadro 2 - Síntese dos usos em beiras de rios e aspectos da morfologia.

\begin{tabular}{|c|c|c|}
\hline Margens fluviais & Aspectos da morfologia & Sistemas territoriais \\
\hline & $\begin{array}{l}\text { Margem fluvial no Bairro } \\
\text { Aparecida (Boca da Bolívia). } \\
\text { Terraço fluvial inundável. } \\
\text { Presença de escadarias de acesso, } \\
\text { barcos populares pequenos, } \\
\text { rabetas e batelões de até } 12 \\
\text { metros pertencentes ao STUR. }\end{array}$ & $\begin{array}{l}\text { Intensa disputa por } \\
\text { espaço entre as } \\
\text { embarcações. Ponto de } \\
\text { conexão da cidade com as } \\
\text { comunidades rurais. } \\
\text { Relações escalares em } \\
\text { nível municipal. }\end{array}$ \\
\hline & $\begin{array}{l}\text { Margem fluvial no Bairro } \\
\text { Aparecida (Rua Pedro Cunha). } \\
\text { Falésia fluvial. Presença de } \\
\text { escadarias, barcos populares, } \\
\text { rabetas e batelões de até } 12 \\
\text { metros pertencentes ao STUR. } \\
\text { Proximidade com casas dos } \\
\text { bairros Aparecida e São Jorge. }\end{array}$ & $\begin{array}{l}\text { Marcações simbólicas e } \\
\text { poucas disputas por } \\
\text { espaço. Ponto utilizado } \\
\text { principalmente por } \\
\text { pessoas que mantêm } \\
\text { casas nas comunidades e } \\
\text { próximas aos locais de } \\
\text { ancoragem. Fluxos em } \\
\text { nível municipal. }\end{array}$ \\
\hline P3 & $\begin{array}{l}\text { Margem fluvial central no Bairro } \\
\text { São Jorge (Rua Pedro Cunha). } \\
\text { Forte centralidade, presença de } \\
\text { barcos do STUR e STUF, flutuantes } \\
\text { e marinas de lanchas } \\
\text { intermunicipais, posto de } \\
\text { gasolina, fábrica de gelo e acesso } \\
\text { ao centro comercial. }\end{array}$ & $\begin{array}{l}\text { Intensa disputa entre } \\
\text { embarcações do STUR e } \\
\text { STUF. Fluxos em nível } \\
\text { municipal e sub-regional. } \\
\text { Relações escalares com } \\
\text { comunidades locais e com } \\
\text { cidades vizinhas. }\end{array}$ \\
\hline P4 & $\begin{array}{l}\text { Margem fluvial no Bairro Centro } \\
\text { (Rua Pedro Cunha). } \\
\text { Forte centralidade, rampas de } \\
\text { acesso, balsa de ferro, lanchas, } \\
\text { balsa de transporte de gado e } \\
\text { barcos médios pertencentes à } \\
\text { pequena burguesia comercial e } \\
\text { pecuaristas locais (STUF). }\end{array}$ & $\begin{array}{l}\text { Intensas disputas entre } \\
\text { embarcações médias e } \\
\text { grandes, demarcações } \\
\text { simbólicas denotando } \\
\text { privatização do espaço } \\
\text { público. Acesso à } \\
\text { concentração comercial. } \\
\begin{array}{l}\text { Fluxos em escalas } \\
\text { regionais. }\end{array}\end{array}$ \\
\hline P5 & $\begin{array}{l}\text { Margem no Bairro São José. } \\
\text { Terraço fluvial inundável e de } \\
\text { difícil acesso. Porto com } \\
\text { instalações improvisadas, } \\
\text { moradias palafíticas e presença de } \\
\text { embarcações pequenas como } \\
\text { canoas e cascos. }\end{array}$ & $\begin{array}{l}\text { Não ocorrem disputas por } \\
\text { espaço, estrutura rústica, } \\
\text { flutuantes de madeira } \\
\text { para acesso e ancoragem. } \\
\text { Pequenas embarcações } \\
\text { de pesca. Fluxos locais. }\end{array}$ \\
\hline
\end{tabular}




\begin{tabular}{|l|l|l|}
\hline P6 & $\begin{array}{l}\text { Margem fluvial no Bairro São } \\
\text { Pedro (Rua Henrique Cunha). }\end{array}$ & $\begin{array}{l}\text { Restrição de acesso ao rio } \\
\text { devido à presença de } \\
\text { vegetação de influência } \\
\text { Planície fluvial inundável. } \\
\text { Presença de poucas moradias } \\
\text { fluvial e pastagem de } \\
\text { galáticas e de pequenas } \\
\text { gado bovino. Baixa } \\
\text { embações como canoas. } \\
\text { dinâmica de fluxos. }\end{array}$ \\
\hline
\end{tabular}

Fonte: Organização dos autores (2020).

Bartoli (2020) aponta que a composição do STUF em Urucará é muito mais significativa do que na cidade vizinha a oeste, São Sebastião do Uatumã (AM), tendo a principal avenida paralela ao paraná de Urucará predominantemente comercial. Supermercados médios e lojas especializadas em determinados itens, como material escolar, materiais de construção e roupas, demonstram maior centralidade do comércio de Urucará, indicado ainda pela margem fluvial central repleta de embarcações tanto do STUR como do STUF (quadro 3).

Quadro 3 - Síntese de entrevistas com proprietários de embarcações populares.

\begin{tabular}{|c|c|c|c|c|c|c|c|c|c|c|c|}
\hline \multicolumn{4}{|c|}{ Função dormitório } & \multicolumn{4}{|c|}{ Ancoragem da embarcação na cidade } & \multicolumn{2}{|c|}{$\begin{array}{l}\text { Vigilância da } \\
\text { embarcação }\end{array}$} & \multicolumn{2}{|c|}{$\begin{array}{l}\text { Dificuldades } \\
\text { para ancorar }\end{array}$} \\
\hline \multicolumn{2}{|c|}{$\begin{array}{c}\text { Tipo de } \\
\text { embarcação }\end{array}$} & Sim & Não & $\begin{array}{l}\text { Período } \\
\text { sazonal }\end{array}$ & $\begin{array}{l}\text { Paraná } \\
\text { de }\end{array}$ & $\begin{array}{c}\text { Boca } \\
\text { da } \\
\text { Bolívi }\end{array}$ & $\begin{array}{c}\text { Igarapé } \\
\text { Taboarizinho }\end{array}$ & $\begin{array}{l}\text { Vigia } \\
\text { pago }\end{array}$ & $\begin{array}{l}\text { Amigo/ } \\
\text { familiar }\end{array}$ & \multicolumn{2}{|c|}{$\begin{array}{l}\text { Disputas por } \\
\text { espaço }\end{array}$} \\
\hline \multirow[t]{2}{*}{ Barco } & \multirow[t]{2}{*}{11} & \multirow{3}{*}{11} & \multirow{3}{*}{01} & Enchente & 10 & 01 & 01 & & \multirow{3}{*}{12} & $\begin{array}{l}\text { O ano } \\
\text { todo }\end{array}$ & 09 \\
\hline & & & & & & & & & & $\mathrm{Na}$ & \\
\hline Canoa & 01 & & & Vazante & 12 & - & - & & & vazante & US \\
\hline \multicolumn{5}{|c|}{ Possui moradia no interior: 12} & \multicolumn{4}{|c|}{ Possui moradia na cidade: 05} & \multicolumn{3}{|c|}{$\begin{array}{c}\text { Fica na casa de parentes na } \\
\text { cidade: } 07\end{array}$} \\
\hline
\end{tabular}

Fonte: Organização dos autores (2020).

Observa-se que a relação STUR e o STUF se manifestam na morfologia urbana de Urucará tanto pelas margens fluviais quanto pelas funções que a economia popular dos bairros contempla ao absorver produtos dos interiores realizando fluxos constantes. No paraná de Urucará, o uso do solo nas margens desse rio se faz pela intensa disputa por espaços, com muitos trechos definidos territorialmente com marcações simbólicas. 
A ausência de políticas públicas de ordenamento territorial se reflete no uso e ocupação irregular do solo, como discutido por Melo (2016), com certos locais se apresentando como área de risco, principalmente em trechos de margens de rios em forma de falésia fluvial, objeto de disputas por embarcações diversas. De acordo com o autor

“Trazendo para o viés da dinâmica ambiental, quando se está fazendo uma análise de um assentamento urbano em uma encosta íngreme, esta representa o perigo (potencial), enquanto a probabilidade de deslizamentos ou desmoronamentos é uma probabilidade (seja ela baixa ou elevada), ou seja, o risco" (MELO, 2016, p.49).

Além do risco ocorre uma disputa desigual entre os setores da economia local, que marginaliza em grande parte os sujeitos que movimentam a economia popular, que passam a ocupar locais de difícil acesso nas proximidades de margens fluviais, com ínfima infraestrutura, o que remete a perspectiva de Sack (2011), na qual o território se coloca enquanto um elemento estratégico, um dispositivo de poder a ser acionado pelos diferentes sujeitos.

Outros subsistemas territoriais são marcantes na economia de Urucará, mas pouco perceptíveis na composição da paisagem urbana. Atualmente a cidade mantém relações escalares diversas (em nível local, regional e internacional), sobretudo a partir dos seguintes subsistemas territoriais: é o segundo maior produtor de guaraná do Estado do Amazonas, tendo vínculos comerciais com grandes empresas fabricantes de bebida; possui intensa atividade pesqueira (presença de colônia e sindicato de pescadores) que abastece o STUR/STUF de Parintins e com vendas de menor quantidade para Maués (AM) e ocasionalmente Santarém (PA); pequena produção de cacau, com vendas para Manaus; e produção mineral na extração de calcário dolomítico, beneficiado no município de Manacapuru (AM). 


\section{CONSIDERAÇÕES FINAIS}

O presente texto buscou evidenciar que o crescimento urbano de Urucará (AM) possui relação com períodos de ascensão e declínio de períodos econômicos e que a interação de sujeitos locais (relação STUR e STUF) dinamiza a economia da cidade e molda o espaço intraurbano. Historicamente, Urucará exerceu função específica na rede urbana regional como fornecedor de matéria prima (borracha e juta, principalmente), tendo sua renda drenada por cidades com maior centralidade como Parintins.

Nas duas últimas décadas a cidade tem experimentado um surto populacional que tem atribuído novas características ao espaço urbano dessa pequena cidade. Fragmentação e dispersão do plano inicial materializam as diferenças socioeconômicas e ampliam-se problemas socioambientais pela carência de infraestrutura, principalmente em áreas de autoconstrução, apresentando apenas 10,9\% de esgotamento sanitário adequado, sendo uma das últimas do Brasil nesse aspecto (IBGE, 2020).

A expansão urbana é condicionada pelo fator sítio que limita ou potencializa sua apropriação. Observa-se que essa expansão já alcançou os limites físicos nas proximidades de cursos fluviais e tende a se expandir pelas estradas em ambiente de terra firme no sentido nordeste/leste do plano inicial, como vem ocorrendo recentemente.

Por fim, a cidade enquanto forma tem possibilitado práticas espaciais a partir de diversas centralidades, conformando um contínuo movimento entre a sede e interiores. Notou-se ainda que assim como em Parintins (BARTOLI, 2017) e Barreirinha (MARQUES; BARTOLI, 2020), a cidade é um espaço de disputas, explícitas nas relações de domínio/ou apropriação de territórios. 


\section{REFERÊNCIAS}

BAENA, A. L. M. Ensaio corográfico sobre a Província do Pará. Edições da Biblioteca do Senado Federal. Vol. 30. Brasília, 2004.

BARTOLI, E. O retorno ao território a partir da cidade: sistemas territoriais urbanoribeirinhos em Parintins (AM) (Tese de Doutorado). UNESP, 2017.

BARTOLI, E. Cidades na Amazônia, sistemas territoriais e a rede urbana. Mercator, v. 17, p. 1$16,2018 a$.

BARTOLI, E. Entre o urbano e o ribeirinho: territorialidades navegantes e sistemas territoriais em Parintins (AM). Espaço Aberto, Rio de Janeiro, v. 8, n.2, p. 169-185, 2018b.

BARTOLI, E. Territorialidades urbano-ribeirinhas: o sistema territorial pesqueiro de Parintins (AM). Geonorte, Manaus, v.13, p. 38-56, 2019.

BARTOLI, E. Cidades pequenas na Amazônia e ordenamento territorial: redes de sujeitos locais e as redes urbanas de Urucará e São Sebastião do Uatumã (AM). Geoingá, Revista do Programa de Pós-Graduação em Geografia, Maringá, p. 80-120, 2020.

BECKER, B. Amazônia: geopolítica na virada do III milênio. Rio de Janeiro: Garamond, 2004.

BECKER, B. A urbe Amazônida. Rio de Janeiro: Garamond, 2013.

BRASIL. Enciclopédia dos municípios brasileiros. IBGE, Rio de Janeiro, 1957.

BROWDER J. O.; GODFREY, B. J. Cidades na floresta. Manaus: EDUA, 2006.

CAPEL, H. La morfologia de las ciudades. Barcelona: Ediciones del Serbal, 2002.

CAPEL, H. Capitalismo y morfología urbana en España. 4 ed. Barcelona: Amelia Romero, 1983.

CORRÊA, R. L. periodização da rede urbana na Amazônia. In: CORRÊA, R. L. (Org). Estudos sobre a rede urbana. Rio de Janeiro: Bertrand Brasil, 2006. p. 181-253.

ENDLICH, A. M. Território e morfologia urbana em pequenas cidades: o que revelam? Revista Geográfica de América Central. Número especial EGAL, p. 1-11, 2011.

FREIRE, J. R. B. A ocupação do Amazonas no século XIX: agricultura e extrativismo. Revista de Comunicação, Manaus, 1984.

GONÇALVES, L. O Amazonas: esboço histórico, corográfico e estatístico até o ano de $1903.1^{\circ}$ edição. H. J. Hanf, Nova York, 1904.

GUERRA, A. T.; GUERRA, A. J. T. Dicionário geológico-geomorfológico. 9a ed. Rio de Janeiro: Bertrand Brasil, 2011. 
IBGE. Instituto Brasileiro de Geografia e Estatística. Disponível em: www.ibge.gov.br, data de acesso: 04 de março de 2020.

JOBIM, A. O Amazonas e sua história: ensaio antropogeográfico e político. Companhia Editora Nacional, São Paulo, 1957.

MACHADO, L. O. A. Urbanização e mercado de trabalho na Amazônia brasileira. Cadernos do IPPUR, Vol.1, 1999.

MARQUES, R. O.; BARTOLI, E. Morfologia urbana da cidade de Barreirinha (AM) e sistemas territoriais: uma proposta metodológica. Revista Geografar. V. 15, n.2, p. 336-357, jul. a dez. 2020.

MEIRELLES, W. Políticas públicas: o planejamento municipal como base para o desenvolvimento sustentável da Amazônia. Manaus: Editora Valer/Uninorte, 2008.

MELO, F. P. Risco ambiental e ordenamento do território em Garanhuns - PE. Tese (Doutorado em Geografia) Universidade Federal de Sergipe, 2016.

MONTE-MÓR, R. L. A urbanização extensiva e lógica de povoamento. In:SANTOS, Milton et. al. (orgs.) Território, globalização e fragmentação. São Paulo: Hucitec/Anpur, 1994.

MORAES, A. O. Peixes, redes e cidades: aspectos socioambientais da pesca comercial de bagres no Médio e Alto Solimões - AM. Dissertação (Mestrado em Ciências do Ambiente e Sustentabilidade na Amazônia) - UFAM, Manaus, 2012.

PAULINO, E. T. Por uma geografia dos camponeses. São Paulo: $2^{\mathrm{a}}$ ed. Editora da UNESP, 2012.

RAFFESTIN, C. Por uma geografia do poder. São Paulo: Ática, 1993 [1980].

REGO, R. L.; MENEGUETTI, K. S. A respeito da morfologia urbana: tópicos básicos para estudos da forma da cidade. Acta Scientiarum. Maringá, v. 33, n. 2, p. 123-127, 2011.

ROSAL, E. Uma análise sobre o ciclo da juta no município de Parintins. Monografia (Graduação em Geografia) Faculdade de Estudos Sociais, Universidade Federal do Amazonas, Manaus, 2000.

SACK, R. O significado de territorialidade. In: DIAS, L.; FERRARI, M. (org.) Territorialidades humanas e redes sociais. Florianópolis: Insular, 2011. P. 5-27.

SANTOS, M. A urbanização brasileira. São Paulo: Hucitec, 1993.

SANTOS, M. A natureza do espaço: técnica e tempo, razão e emoção. São Paulo: HUCITEC, 1996.

TENÓRIO, B. Fundamentos de Urucará. Parintins: Gráfica João XXIII, 2016. 
TRINDADE JR, S. C. C. Diferenciação territorial e urbanodiversidade: elementos para pensar uma agenda urbana em nível nacional. Cidades, Presidente Prudente, Grupo de Estudos Urbanos, v.7, n.12, p. 227-225, 2010.

URBAN, G. A história da cultura brasileira segundo as línguas nativas. In: Carneiro da cunha, M. (org.), História dos Índios no Brasil. Companhia das Letras, São Paulo, 1992. pp. 87-102.

WITACKER, A.; MIYAZAKI, V. O estudo das formas urbanas no âmbito da geografia urbana. Apontamentos metodológicos. Revista de Geografia e Ordenamento do Território, $n^{\circ} 2$. $p$. 307-327, 2012.

WRIGHT, R. M. Os Povos indígenas no Brasil hoje. Programa de TV/Entrevista, 2003.

\section{1 - Rildo Oliveira Marques:}

Mestre em Geografia pela Universidade Federal do Amazonas

https://orcid.org/0000-0003-3034-056X - rildomarques.geo@gmail.com

Contribuição: morfologia urbana, geografia física, procedimentos metodológicos, cartografia, pesquisa de campo, redação final, formatação e revisão.

\section{2 - Arenilton Monteiro Serrão:}

Mestre em Geografia pela Universidade Federal do Amazonas https://orcid.org/0000-0003-4173-4812 - arenilton2@gmail.com Contribuição: aspectos históricos, questões agrárias, investigação, pesquisa de campo, levantamento bibliográfico e redação.

\section{3 - Estevan Bartoli:}

Doutor em Geografia pela Unesp - Presidente Prudente https://orcid.org/0000-0003-1238-3187 - estevangeo@hotmail.com Contribuição: sistemas territoriais, território, geografia urbana, pesquisa de campo, supervisão, redação e revisão

\section{Como citar este artigo}

MARQUES, R. O.; SERRÃO, A. M.; BARTOLI, E. Ciclos econômicos, morfologia urbana e sistemas territoriais em Urucará (AM). Geografia Ensino \& Pesquisa, Santa Maria, v. 25, e30, p. 1-31, 2021. DOI 10.5902/2236499453316. Disponível em: https://doi.org/10.5902/2236499453316. Acesso em: dia mês abreviado. ano. 